\title{
The social determinants of health as predictors of adherence to public health preventive measures among parents and young children during the COVID-19 pandemic: a longitudinal cohort study
}

\author{
Yulika Yoshida-Montezuma ${ }^{1}$ (D) $\cdot$ Charles D. G. Keown-Stoneman ${ }^{2,3}$ (D) Susitha Wanigaratne ${ }^{4,5,6}$ (D) Xuedi Li $^{4}$ (D) \\ Shelley M. Vanderhout ${ }^{2,7}$ (D) - Cornelia M. Borkhoff ${ }^{4,8,9,10}$ (D) Catherine S. Birken $^{4,8,11,12} \cdot$ Jonathon L. Maguire ${ }^{2,7,8,11,12}$. \\ Laura N. Anderson ${ }^{1,4}$ (D)
}

Received: 1 December 2020 / Accepted: 3 May 2021 / Published online: 28 May 2021

(C) The Canadian Public Health Association 2021

\begin{abstract}
Objectives To investigate whether social determinants of health (SDOH) are predictive of adherence to public health preventive measures and to describe changes in adherence over time among parents and children.

Methods A longitudinal study was conducted in children aged 0-10 years and their parents through the TARGet Kids! COVID19 Study in the Greater Toronto Area, Canada (April-July 2020). This study included 335 parents (2108 observations) and 416 children (2632 observations). Parents completed weekly questionnaires on health, family functioning, socio-demographics, and public health practices. The outcome was adherence to public health preventive measures measured separately for parents and children. Marginal log-binomial models were fitted using repeated measures of the outcome and predictors.

Results Unemployment (RR 0.67, 95\% CI: 0.47, 0.97), apartment living (RR 0.72, 95\% CI: 0.53, 0.99), and essential worker in the household (RR $0.74,95 \%$ CI: 0.55, 1.00) were associated with decreased likelihood of adherence among parents; however, no associations were observed for other SDOH, including family income and ethnicity. Furthermore, there was no strong evidence that SDOH were associated with child adherence. The mean number of days/week that parents and children adhered at the start of the study was $6.45(\mathrm{SD}=0.93)$ and $6.59(\mathrm{SD}=0.86)$, respectively, and this decreased to $5.80(\mathrm{SD}=1.12)$ and $5.84(\mathrm{SD}=1.23)$ by study end. Children consistently had greater adherence than parents.

Conclusion SDOH were predictive of adherence to public health preventive measures among parents but less so in children among our sample of relatively affluent urban families. Adherence was high among parents and children but decreased over time. Equitable approaches to support the implementation of public health guidelines may improve adherence.
\end{abstract}

Laura N. Anderson

ln.anderson@mcmaster.ca

1 Health Research Methods, Evidence, and Impact, McMaster University, 1280 Main Street W, Hamilton, Ontario L8S 4L8, Canada

2 Li Ka Shing Knowledge Institute, St. Michael's Hospital, Unity Health Toronto, Toronto, Ontario, Canada

3 Dalla Lana School of Public Health, University of Toronto, Toronto, Ontario, Canada

4 Child Health Evaluative Sciences, The Hospital for Sick Children, Toronto, Ontario, Canada

5 ICES, Sunnybrook Health Sciences Centre, Toronto, Ontario, Canada

6 MAP Centre for Urban Health Solutions, Unity Health Toronto, Toronto, Ontario, Canada
7 Department of Pediatrics, St. Michael's Hospital, Unity Health Toronto, Toronto, Ontario, Canada

8 Institute of Health Policy, Management and Evaluation, Dalla Lana School of Public Health, University of Toronto, Toronto, Ontario, Canada

9 Division of Pediatric Medicine, The Hospital for Sick Children, Toronto, Ontario, Canada

10 Women's College Research Institute, Women's College Hospital, Toronto, Ontario, Canada

11 Department of Pediatrics, Faculty of Medicine, University of Toronto, Toronto, Ontario, Canada

12 Department of Nutritional Sciences, Faculty of Medicine, University of Toronto, Toronto, Ontario, Canada 


\section{Résumé}

Objectifs Voir si les déterminants sociaux de la santé (DSS) sont des prédicteurs de conformité aux mesures de prévention sanitaire et décrire l'évolution de la conformité des parents et des enfants au fil du temps.

Méthode Nous avons mené une étude longitudinale auprès d'enfants de 0 à 10 ans et de leurs parents dans le cadre de l'étude sur la COVID-19 menée par le groupe de recherche TARGet Kids! dans la région du Grand Toronto, au Canada (avril à juillet 2020). L'étude incluait 335 parents (2 108 observations) et 416 enfants (2 632 observations). Les parents ont rempli un questionnaire hebdomadaire sur la santé, le fonctionnement familial, le profil sociodémographique et les pratiques sanitaires. Le résultat était la conformité aux mesures de prévention sanitaire, mesurée séparément pour les parents et les enfants. Des modèles log-binomiaux marginaux ont été ajustés à l'aide de mesures répétées du résultat et des prédicteurs.

Résultats Le chômage (RR 0,67, IC de $95 \%: 0,47,0,97$ ), la vie en appartement (RR 0,72, IC de 95\%:0,53,0,99) et la présence d'un travailleur essentiel dans le ménage (RR 0,74, IC de $95 \%: 0,55,1,00)$ étaient associés à une probabilité réduite de conformité chez les parents; par contre, aucune association n'a été observée pour les autres DSS, dont le revenu familial et l'ethnicité. Il n'y avait pas non plus d'indications convaincantes d'une association entre les DSS et la conformité chez les enfants. Le nombre moyen de jours/semaine où parents et enfants s'étaient conformés aux mesures de prévention sanitaire au début de l'étude était de $6,45(\mathrm{~S}=0,93)$ et de $6,59(\mathrm{~S}=0,86)$, respectivement; ce nombre a diminué pour atteindre $5,80(\mathrm{~S}=1,12)$ et 5,84 $(\mathrm{S}=1,23)$ à la fin de l'étude. La conformité des enfants était uniformément supérieure à celle des parents.

Conclusion Dans notre échantillon de familles urbaines relativement aisées, les DSS étaient des prédicteurs de conformité aux mesures de prévention sanitaire chez les parents, mais dans une moindre mesure chez les enfants. La conformité était élevée chez les parents comme chez les enfants, mais elle a diminué avec le temps. Des stratégies équitables d'appui à l'application des directives sanitaires pourraient améliorer le respect de ces directives.

Keywords COVID-19 $\cdot$ Physical distancing $\cdot$ Public health $\cdot$ Pandemic $\cdot$ Parents $\cdot$ Children

Mots-clés COVID-19 · distanciation physique · santé publique · pandémie · parents · enfants

\section{Introduction}

Public health measures and guidelines have been pivotal in reducing the transmission of severe acute respiratory syndrome coronavirus 2 (SARS-CoV-2) and mitigating the impact of the COVID-19 pandemic (Government of Canada, 2020). In Canada, a phased approach to restrictions has been used to control spread over the course of the pandemic. Starting in March 2020, restrictions were implemented in Ontario that included closures of schools and non-essential businesses, restrictions on gathering sizes, stay-at-home orders, and widespread closure or restriction of access to outdoor spaces; many of these restrictions were relaxed in the summer of 2020 as the first wave of the pandemic waned (Detsky \& Bogoch, 2020; Toronto.com, 2020). Despite the phased approach to reopening, public health preventive measures, including handwashing and maintaining physical distancing, have continued to be widely recommended (Government of Canada, 2020). In Canada, physical distancing recommendations have included avoiding crowded places, reducing non-essential travel and trips, commuting outside of the busiest hours if using public transportation, avoiding greetings that include physical contact, following local guidelines on gathering sizes, and keeping a distance of 2 metres (Government of Canada, 2020). A recent systematic review of over 170 studies indicated that current policies of maintaining at least $1 \mathrm{~m}$ when physical distancing was strongly associated with a large reduction in infection (pooled adjusted odds ratio $0.18,95 \%$ confidence interval $0.09,0.38$ ) with distances of $2 \mathrm{~m}$ potentially being more effective (Chu et al., 2020).

There have been several studies conducted globally on the predictors of adherence to public health preventive measures, most of which have been in adults (Barari et al., 2020; Brankston et al., 2020; Brzezinski et al., 2020; Carvalho et al., 2020; Coroiu et al., 2020; Farias \& Pilati, 2020; Freeman et al., 2020; Harper et al., 2020; Papageorge et al., 2021; Papanastasiou et al., 2020; Travaglino \& Moon, 2020). However, little is known about adherence to public health preventive measures in Canada, in particular among parents and young children. Disparities in COVID-19 infection and outcomes have been observed in many cities, including Toronto, suggesting that the social determinants of health (SDOH), such as race, ethnicity, income, gender, and household size, may increase COVID-19 risk (City of Toronto, 2020; Mein, 2020; Office of National Statistics, 2020; Public Health Ontario, 2020a). It is currently unknown whether these social determinants are associated with physical distancing and handwashing practices. Thus, it is important to understand the factors that are associated with adherence to public health preventive measures to inform governmental policy today and for the months and years to come as recurrent outbreaks of SARS-CoV-2 are projected to occur (Kissler et al., 2020). The primary objective of this study was to 
investigate whether the $\mathrm{SDOH}$ were predictive of adherence to public health preventive measures among parents and young children during the first several months of the SARSCoV-2 pandemic in Ontario, Canada. The secondary objective was to describe changes in adherence over time.

\section{Methods}

\section{Study design and participants}

The TARGet Kids! (The Applied Research Group for Kids) COVID-19 Study of Children and Families is an ongoing prospective longitudinal observational study of children and families followed during the COVID-19 pandemic from April 2020. Healthy children from 0 to 10 years (inclusive) and their parents enrolled in the ongoing TARGet Kids! primary care pediatric network in the Greater Toronto Area were recruited to participate by telephone. TARGet Kids! has recruited children since 2008 from pediatric or family practice clinics in the Greater Toronto Area and has collected data at each regularly scheduled well-child visit. It has been described previously (www.clinicaltrials.gov: NCT01869530). Exclusion criteria for initial recruitment into the TARGet Kids! cohort include: children with associated health conditions affecting growth (e.g., failure to thrive, cystic fibrosis), children with any acute or chronic conditions (other than asthma and high functioning autism), children with severe developmental delay, and families who are unable to communicate in English (Carsley et al., 2015).

Families enrolled in the TARGet Kids! COVID-19 Study of Children and Families were asked to complete weekly questionnaires either over the telephone or online through the Research Electronic Data Capture (REDCap) about occupation, subsidies, financial security, mental health, physical health, health behaviours, substance use, family dynamics, parenting, childcare arrangements, eating behaviours, and public health preventive measures. Parents completed questionnaires on behalf of themselves and their children. Recruitment for the TARGet Kids! COVID-19 Study of Children and Families started in March 2020 and is ongoing throughout the pandemic. Data were prospectively collected each week from the initial visit onwards. To follow up with respondents, all invited participants were sent two email reminders and one phone call. Data from April 14 to July 15, 2020 were used for this study. Public data on COVID-19 cases per day in Toronto were downloaded from the City of Toronto on September 26, 2020 (City of Toronto, 2020). Daily case numbers based on episode date were used from April 14 to July 15, 2020.

\section{Ethics}

Informed verbal consent was provided over the telephone. Parents of all children participating in the TARGet Kids! cohort study provided informed written consent at enrollment. Ethics approval was provided by the Research Ethics Boards at both The Hospital for Sick Children and Unity Health Toronto.

\section{Predictors}

Predictors were selected a priori and included social determinants of health (age, sex, income, unemployment, ethnicity, housing) and other variables hypothesized to be associated with adherence to public health preventive measures (essential worker status, child living arrangement, older adults living in the household, parent currently pregnant, attending childcare, family history of chronic disease). Information on predictors was collected from two sources: (1) TARGet Kids! COVID19 Study of Children and Families and (2) data already collected (pre-COVID) as part of the TARGet Kids! standardized, parent-completed questionnaire.

Data collected through the TARGet Kids! COVID-19 Study of Children and Families were used for the following variables: child's age, parent's age, household essential worker status, parent unemployment due to COVID-19, number of people in household, number of people in household 60 years or older, family history of chronic disease (includes heart disease, diabetes, lung disease, cancer, or chronic disease), pregnancy status, child currently attending childcare, and calendar time. Number of people in household was categorized as: (1) four or less or (2) five or greater using the open-ended question, "How many people are currently in your household?" Family history of chronic disease was ascertained through the question, "Does anybody in the household have a medical history of heart disease/diabetes/lung disease/cancer/chronic disease?" The question had a five-item response to capture whether any of the conditions were present in the family and which relative(s) had the condition(s). Family history of chronic disease was recategorized into two categories: (1) yes or (2) no, where families who answered "yes" had at least one of the above conditions. Household essential worker status, unemployment due to COVID-19, number of people in household 60 years or older, pregnancy status, and child currently attending childcare were ascertained through closed-ended "yes" or "no" questions. Calendar time was defined continuously in weeks using the weekly visit date. Child's age, parent's age, unemployment due to COVID-19, and calendar time were timevarying variables taken from repeated visits.

Pre-COVID-19 data were used for the following variables: child's sex, parent's sex, family income before taxes, median after-tax household income, maternal ethnicity, paternal 
ethnicity, child living arrangement, and dwelling type. A closed-ended question with 10 response options was used to measure family income and was recategorized as: (1) less than $\$ 60,000$; (2) $\$ 60,000$ to $\$ 149,999$; and (3) $\$ 150,000$ or more. Neighbourhood median after-tax household income was obtained using the Statistics Canada Postal Code Conversion File and data from the 2006 Canadian Census (Wilkins, 2009) and was categorized as: (1) less than $\$ 60,000 ;(2)$ $\$ 60,000$ to $\$ 99,999$; and (3) $\$ 100,000$ or more. A closedended question with 20 response options was used to determine the ethnicity of the biological mother and father, allowing for multiple response options to capture mixed ethnicity. Ethnicity was then categorized into 4 categories informed by recent knowledge on COVID-19 risk in the Province of Ontario: (1) European; (2) African, Southeast Asian, South Asian; (3) Arab, Latin American, East Asian; and (4) mixed (Guttmann et al., 2020). Child living arrangement was obtained from the question, "Which of the following best describes your child's living arrangement?" and was categorized as: (1) both parents living in the same household; (2) lives alternating with 2 parents in different households; and (3) lives with one parent only. Child dwelling was ascertained by asking the question, "Do you live in a house or apartment?" and responses were categorized as: (1) house or (2) apartment.

\section{Outcome}

The primary outcome was adherence to public health preventive measures which was defined as practicing public health preventive measures, including staying home, limiting the number of visitors in the home, avoiding contact with others, keeping a distance of $2 \mathrm{~m}$ or more, and handwashing. The cohort was followed up weekly to ascertain their responses to the closed-ended questions: "Out of the last 7 days, how many days have you and your child been practicing the following: (1) staying home; (2) limiting the number of visitors in your home; (3) avoiding contact with others; (4) keeping distance ( $2 \mathrm{~m}$ or more) from others; and (5) practicing frequent hand washing?" At the time of questionnaire development, mask use was not recommended and was therefore not asked. The number of days each week that parents and children separately practiced each of the five preventive measures was summed for a maximum of 35 . For our primary analysis, the outcome of adherence to public health preventive measures was dichotomized to create the complete adherence category (35 out of 35) versus incomplete adherence category ( $<35$ out of 35 ) for each week. A supplementary analysis was conducted which separately evaluated complete ( 7 out of 7 ) versus incomplete adherence for the following three individual public health measures: "staying home", "limiting visitors", and "avoiding contact". These three measures were evaluated separately since they showed the greatest decline from April to July 2020. As a secondary supplementary analysis, we evaluated the outcome of daily adherence to any public health preventive measures as a binomial count variable by taking the total number of days practiced for the five preventive measures, out of a maximum of 35 .

\section{Statistical analysis}

For the primary analysis, unadjusted and adjusted risk ratios (RR) with $95 \%$ confidence intervals (CI) were estimated for each predictor separately in relation to complete versus incomplete adherence to public health preventive measures using marginal log-binomial regression models (generalized estimating equations with a log link function) including repeated measures of predictors and outcomes using PROC GEE (SAS version 9.4; SAS Institute, Inc.). Marginal models were used to account for clustering within a family for siblings and repeated measures over time within subject. An independent correlation matrix was used which had a better model fit than an exchangeable structure as determined by the lower quasi-likelihood under the independence model criterion (QIC) goodness of fit statistic value. A priori, our modelbuilding strategy was to evaluate each $\mathrm{SDOH}$ predictor variable separately in relation to adherence to public health preventive measures, and adjusted for only child's age, child's sex, parent's age, parent's sex, and calendar time. Models were run separately for parents (335 parents with 2108 observations) and children (416 children with 2632 observations). As a post hoc supplemental analysis, a fully adjusted model including all predictors in one model in relation to complete versus incomplete adherence was conducted. For the fully adjusted model, multicollinearity was assessed using the variance inflation factors (VIF) and all VIF were $<2$, which did not suggest high correlation between predictors.

Missingness for each predictor was $22 \%$ or less. To avoid bias introduced from missing data or the use of single-value imputation methods, we performed multiple imputation $(n=20)$ to impute missing predictor data using PROC MI and PROC MIANALYZE in SAS. For the secondary supplementary analysis, adjusted RR and 95\% CI were estimated for each predictor in relation to the average daily probability of adherence to public health preventive measures using marginal log-binomial count regression models including repeated measures of predictors and outcomes using PROC GEE (SAS version 9.4; SAS Institute, Inc.).

\section{Results}

A total of 335 parents (2108 observations) and 416 children (2632 observations) were included after the removal of implausible values (e.g., $<15$ years for parent age and $>7$ days for questions regarding weekly public health preventive measures) for the predictors and outcome. A detailed flowchart 
of study participants is presented in Fig. 1. Descriptive characteristics of participants are shown in Table 1. The mean age of parent respondents was 38 years and $93 \%$ were female. The mean age of children was 4.4 years, $48 \%$ were female, and $64 \%$ had mothers of European ethnicity.

Between April 14 and July 15, 2020, participants submitted an average of 6.3 weekly questionnaires over the telephone or online (Table 1). Most participants completed between 2 and 10 questionnaires (79\%) while $11 \%$ of participants completed 1 questionnaire and 10\% completed 10-21 questionnaires. For the first questionnaire, the average number of days that parents and children adhered to public health preventive measures was 6.6 and 6.5 days per week, respectively. For the last questionnaire, the average number of days that both parents and children adhered to public health preventive measures was 5.8 days per week (Table 1). The average number of days that parents and children adhered to the individual public health preventive measures is provided in Supplementary Figures 1 and 2, respectively. Compared with COVID-19 cases in Toronto which experienced a steep decline from April 14 through July 15, the average number of days per week parents reported "washing hands" stayed relatively consistent while parent report of "limiting visitors", "keeping distance of $2 \mathrm{~m}$ or more", "avoiding others" and "staying home" declined over time with "limiting visitors" witnessing the least decline and "staying home" witnessing the greatest decline over time (Fig. 2). The reported average number of days per week for children "limiting visitors" and "washing hands" declined slightly from April 14 to July 15, 2020, while the average reported number of days per week for children "avoiding others", "staying home" and "keeping distance of $2 \mathrm{~m}$ or more" declined more over time (Fig. 3).

In the adjusted analysis for parents (Table 2), there was evidence that several SDOH were predictive of adherence to public health preventive measures. Parent unemployment due to COVID-19 (RR 0.67, 95\% CI: 0.47, 0.97), living in an apartment (RR 0.72, 95\% CI: 0.53, 0.99), and having an essential worker in the household (RR $0.74,95 \%$ CI: $0.55,1.00$ ) predicted decreased likelihood of adherence compared with their respective reference group, after adjusting for parent age, parent sex, child age, child sex, and calendar time. The adjusted RR for the association between alternating or singleparent household living arrangement compared with both parents in the same household and adherence versus incomplete adherence to public health preventive measures was 0.42 (95\% CI: 0.17, 1.01). Estimates for the post hoc fully adjusted model including all predictors in one model are found in Supplementary Table 1. Sensitivity analysis evaluating the outcomes "staying home", "limiting visitors", and "avoiding contact" separately is provided in Supplementary Table 3. Results for each of the three parent outcomes separately were similar to the combined results and the direction of the observed associations was similar for each outcome.

In the adjusted analysis for children (Table 3), few SDOH were predictive of adherence. There was evidence that living in an apartment (RR 0.80, 95\% CI: 0.64, 1.00); mixed parental ethnicity (RR 0.76, 95\% CI: 0.61, 0.95); and living in a household with 4 or less people (RR $0.85,95 \%$ CI: $0.73,0.98$ ) were associated with decreased likelihood of adherence to public health preventive measures after adjusting for parent age,

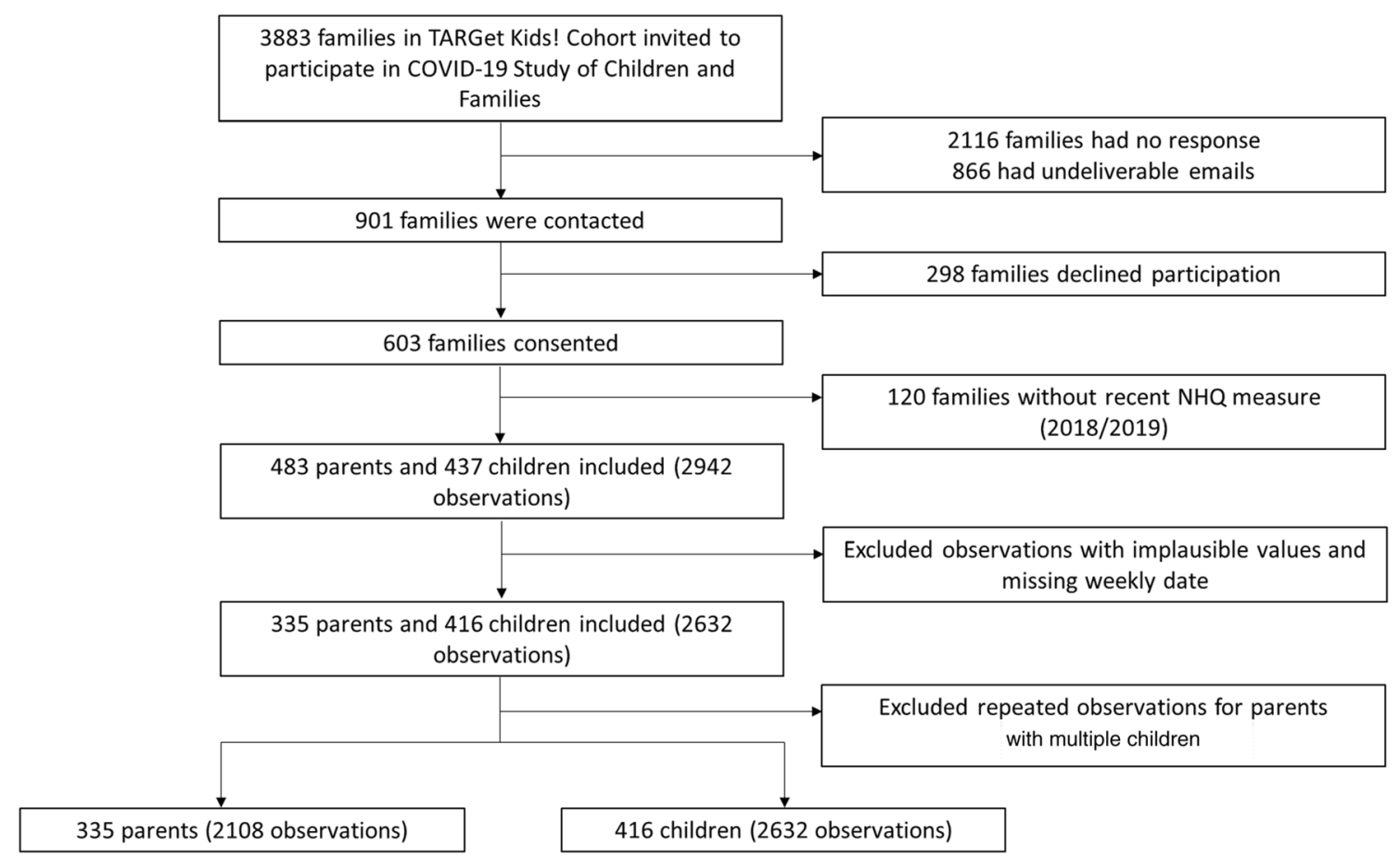

Fig. 1 Flowchart of study participants in the TARGet Kids COVID-19 Study 
Table 1 Descriptive characteristics of study participants for parents $(N=335)$ and children $(N=416)$ in the TARGet Kids COVID-19 Study from April to July 2020 in the Greater Toronto Area

\begin{tabular}{|c|c|c|}
\hline Characteristic & $N(\%)$ missing & Mean (SD) or $N(\%)$ \\
\hline Child age (mean months and SD) ${ }^{1}$ & $0(0 \%)$ & $53(31.4)$ \\
\hline Child sex ${ }^{1}$ & $0(0 \%)$ & \\
\hline Female & & $201(48 \%)$ \\
\hline Male & & $215(52 \%)$ \\
\hline Parent age (mean years and SD) & $31(9 \%)$ & $38(4.9)$ \\
\hline Parent sex & $0(0 \%)$ & \\
\hline Female & & $312(93 \%)$ \\
\hline Male & & $23(7 \%)$ \\
\hline Number of weekly questionnaire submissions (mean and SD) & $0(0 \%)$ & $6.3(3.6)$ \\
\hline Child adherence to public health measures (mean and SD) & $1(1 \%)$ & \\
\hline Number of days per week at first submission & & $6.59(0.86)$ \\
\hline Number of days per week at last submission & & $5.84(1.23)$ \\
\hline Parent adherence to public health measures (mean and SD) & $1(1 \%)$ & \\
\hline Number of days per week at first submission & & $6.45(0.93)$ \\
\hline Number of days per week at last submission & & $5.80(1.12)$ \\
\hline Maternal ethnicity & $70(21 \%)$ & \\
\hline European & & $169(64 \%)$ \\
\hline African, Southeast Asian, South Asian & & $36(14 \%)$ \\
\hline Arab, Latin American, East Asian & & $35(13 \%)$ \\
\hline Mixed & & $25(9 \%)$ \\
\hline Paternal ethnicity & $75(22 \%)$ & \\
\hline European & & $184(71 \%)$ \\
\hline African, Southeast Asian, South Asian & & $33(13 \%)$ \\
\hline Arab, Latin American, East Asian & & $20(8 \%)$ \\
\hline Mixed & & $23(9 \%)$ \\
\hline Unemployed due to COVID- $19^{2}$ & $11(1 \%)$ & \\
\hline Yes & & $244(13 \%)$ \\
\hline No & & $1853(87 \%)$ \\
\hline Family income & $57(17 \%)$ & \\
\hline Less than $\$ 60,000$ & & $24(9 \%)$ \\
\hline$\$ 60,000$ to $\$ 149,999$ & & $96(34 \%)$ \\
\hline$\$ 150,000$ or more & & $158(57 \%)$ \\
\hline Median neighbourhood household income & $8(2 \%)$ & \\
\hline Less than $\$ 60,000$ & & $86(26 \%)$ \\
\hline$\$ 60,000$ to $\$ 99,999$ & & $191(59 \%)$ \\
\hline$\$ 100,000$ or more & & $50(15 \%)$ \\
\hline Essential worker & $0(0 \%)$ & \\
\hline Yes & & $111(33 \%)$ \\
\hline No & & $224(67 \%)$ \\
\hline Child living arrangement & $52(15 \%)$ & \\
\hline Both parents in the same household & & $273(96 \%)$ \\
\hline Single-parent household & & $8(3 \%)$ \\
\hline Alternating household & & $2(1 \%)$ \\
\hline Dwelling type & $99(29 \%)$ & \\
\hline Apartment & & $36(15 \%)$ \\
\hline House & & $200(85 \%)$ \\
\hline Number of people in the household & $25(7 \%)$ & \\
\hline 4 or less & & $250(81 \%)$ \\
\hline 5 or more & & $60(19 \%)$ \\
\hline
\end{tabular}


Table 1 (continued)

\begin{tabular}{lcc}
\hline Characteristic & $N(\%)$ missing & Mean (SD) or $N(\%)$ \\
\hline Household member age 60 or older & $18(5 \%)$ & $26(8 \%)$ \\
Yes & & $291(92 \%)$ \\
No & $21(6 \%)$ & $54(17 \%)$ \\
Child currently attends childcare & & $260(83 \%)$ \\
Yes & $19(6 \%)$ & $11(3 \%)$ \\
No & & $305(97 \%)$ \\
Parent is currently pregnant & & $88(28 \%)$ \\
Yes & $21(6 \%)$ & $226(72 \%)$ \\
No & & \\
Femily history of chronic disease 3 & & \\
No & & \\
\hline
\end{tabular}

${ }^{1}$ The predictors of child age and child sex were based on the sample size for children $(N=416)$ while all other predictors were based on the sample size for parents $(N=335)$

${ }^{2} N$ represents the number of observations $(N=2108)$ since the predictor was measured weekly

${ }^{3}$ Includes heart disease, diabetes, lung disease, cancer, or chronic disease for anybody in the household

parent sex, child age, child sex, and calendar time. The adjusted RR for the association between alternating household living arrangement compared with both parents in the same household and adherence versus incomplete adherence to public health preventive measures was 1.34 (95\% CI: 0.98, 1.84). Estimates for the post hoc fully adjusted model are found in Supplementary Table 2. Similar results were obtained for the supplementary analysis using the separate outcomes (Supplementary Table 4), although some additional statistically significant predictors of adherence to limiting visitors were observed, including the child currently attending childcare (RR $0.90,95 \%$ CI: $0.83,0.97$ ) and family history chronic disease (RR 0.92, 95\% CI: 0.88, 0.98).

Similar results were found for the secondary supplementary analysis using marginal log-binomial count regression models for the outcome of average daily probability of adhering to public health preventive measures practices. However, effect sizes were smaller due to the scale of the outcome. For parents, unemployment due to COVID-19 and living in an apartment still predicted less adherence but were no longer
Fig. 2 LOESS smoothing average number of days per week parents practiced each of the 5 public health measures ( $y 1$-axis) as self-reported from April 14 to July 15,2020 , and corresponding data from Toronto Public Health from the same time period on the COVID-19 cases per day (y2-axis)

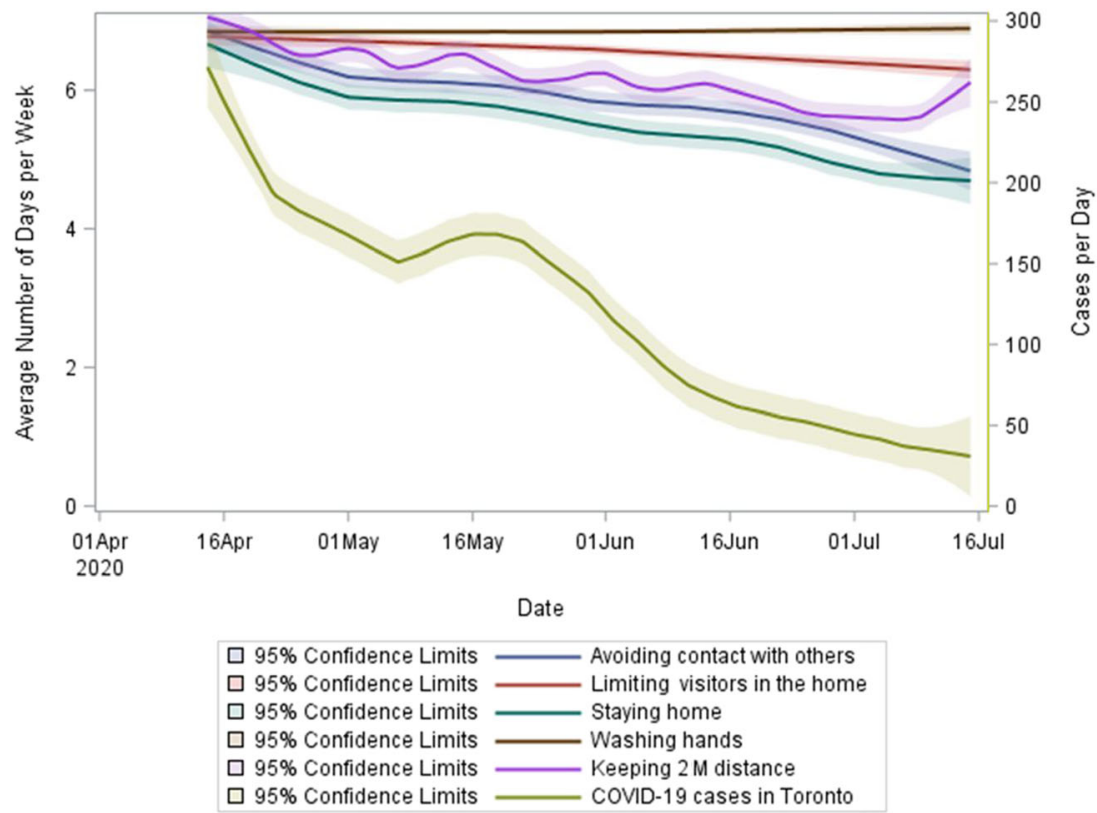


Fig. 3 LOESS smoothing average number of days per week children practiced each of the 5 public health measures ( $y 1$-axis) as reported by their parents from April 14 to July 15,2020 , and corresponding data from Toronto Public Health from the same time period on the COVID-19 cases per day ( $y 2$-axis)

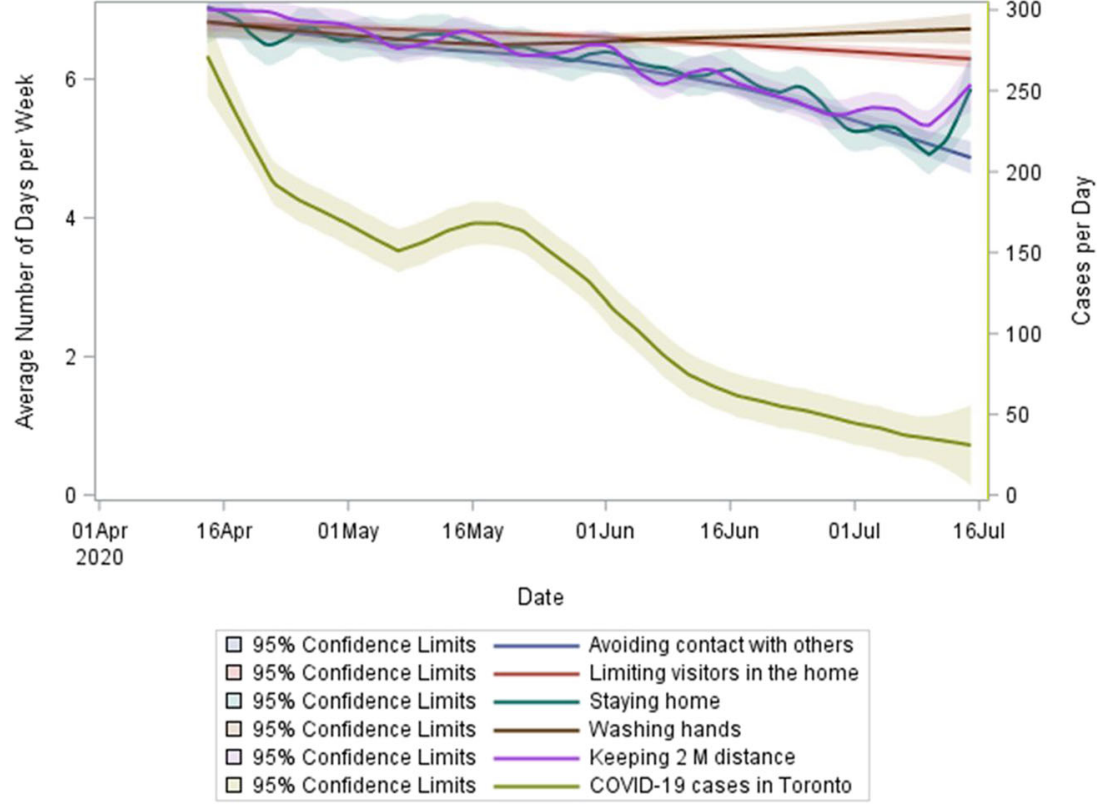

significant, while a family income of between $\$ 60,000$ and $\$ 149,999$ became a significant predictor of less adherence on any given day (Supplementary Table 5). For children, an essential worker living in the household, currently attending daycare, and family history of chronic disease became significant predictors of less adherence on any given day (Supplementary Table 6).

\section{Discussion}

The SDOH were predictive of adherence to public health preventive measures for parents but less so for their young children among this study population during the first several months of the pandemic between April 14 and July 15, 2020 in the Greater Toronto Area. Over this period, adherence to public health measures was high for both parents and children with a decline over time.

The considerable decline in average adherence to public health preventive measures corresponded to easing of public health restrictions (Government of Ontario, 2020) and a decrease in the number of COVID-19 cases in the city of Toronto over the same time period (City of Toronto, 2020). Greater adherence to public health preventive measures was consistently observed for children as compared with parents, suggesting that parents may be more protective of their children's behaviours than their own. School closures during this period may also have allowed children to physically distance (Public Health Ontario, 2020b). It should be noted that public health guidelines regarding public health preventive measures changed over the study period while our measures of public health preventive measures and our definition of adherence did not change.
Previous research analyses investigating the relationship between the SDOH and adherence to public health preventive measures during COVID-19 found that younger adults and males had less adherence (Brankston et al., 2020; Brouard et al., 2020; Coroiu et al., 2020; Papanastasiou et al., 2020). We found modest but non-significant evidence that younger parents were less likely to adhere. However, we also found modest but non-significant evidence that female parents were also less likely to adhere. Pre-pandemic and pandemic healthcare behavioural research indicates that women are more likely than men to follow health-care guidelines (Olcaysoy Okten et al., 2020; Rogers et al., 2010). However, women have been shown to constitute the majority of essential workers, such as in grocery stores, healthcare, long-term care, and childcare (Canadian Women's Foundation, 2020; Public Health Ontario, 2020a), which may help explain the structural factors that impact the ability to adhere.

Studies have found that those able to work from home or who had flexible work arrangements were better able to adhere to public health preventive measures (Brankston et al., 2020; Papageorge et al., 2021; Papanastasiou et al., 2020) while those living in apartments were less able to adhere (Papanastasiou et al., 2020). Consistent with these results, we found that parents who were essential workers and parents and children living in apartments were less able to adhere to public health preventive measures. These findings were expected as essential workers required to work in-person and those living in smaller spaces may find it more challenging to physically distance. Parent unemployment due to COVID-19 was associated with decreased likelihood of adherence to public health preventive measures in parents, which could be explained by their having more time to run essential errands and needing to find work. An alternating household living arrangement for 
Table 2 Unadjusted and adjusted risk ratios (RR) and 95\% confidence intervals (CI) for the association between social determinants of health and parents' average weekly adherence versus incomplete adherence to public health measures during the COVID-19 pandemic from April to July 2020 ( $n=335$ unique parents and 2108 repeated observations) estimated using marginal log-binomial regression models

Parent

\begin{tabular}{|c|c|c|}
\hline Explanatory variable & Unadjusted RR (95\% CI) & Adjusted $\mathrm{RR}^{1}(95 \% \mathrm{CI})$ \\
\hline Parent age ${ }^{2}$ & $1.01(0.99,1.03)$ & $1.02(0.99,1.05)$ \\
\hline \multicolumn{3}{|l|}{ Parent sex } \\
\hline Female & $0.66(0.45,0.96)$ & $0.70(0.47,1.05)$ \\
\hline Male & REF & REF \\
\hline \multicolumn{3}{|l|}{ Family income } \\
\hline Less than $\$ 60,000$ & $0.96(0.64,1.44)$ & $1.01(0.68,1.51)$ \\
\hline$\$ 60,000$ to $\$ 149,999$ & $0.83(0.63,1.08)$ & $0.80(0.61,1.04)$ \\
\hline$\$ 150,000$ or more & REF & REF \\
\hline \multicolumn{3}{|l|}{ Median neighbourhood household income } \\
\hline Less than $\$ 60,000$ & $0.84(0.57,1.25)$ & $0.81(0.55,1.20)$ \\
\hline$\$ 60,000$ to $\$ 99,999$ & $0.92(0.66,1.28)$ & $0.92(0.67,1.28)$ \\
\hline$\$ 100,000$ or more & REF & REF \\
\hline \multicolumn{3}{|l|}{ Unemployed due to COVID-19 } \\
\hline Yes & $0.65(0.44,0.95)$ & $0.67(0.47,0.97)$ \\
\hline No & REF & REF \\
\hline \multicolumn{3}{|l|}{ Dwelling type } \\
\hline Apartment & $0.72(0.53,0.98)$ & $0.72(0.53,0.99)$ \\
\hline House & REF & REF \\
\hline \multicolumn{3}{|l|}{ Maternal ethnicity } \\
\hline African, Southeast Asian, South Asian & $0.92(0.62,1.37)$ & $0.94(0.64,1.37)$ \\
\hline Arab, Latin American, East Asian & $0.93(0.63,1.38)$ & $0.89(0.60,1.34)$ \\
\hline Mixed & $0.93(0.64,1.35)$ & $0.93(0.62,1.38)$ \\
\hline European & REF & REF \\
\hline \multicolumn{3}{|l|}{ Paternal ethnicity } \\
\hline African, Southeast Asian, South Asian & $0.99(0.68,1.46)$ & $1.02(0.70,1.48)$ \\
\hline Arab, Latin American, East Asian & $0.95(0.62,1.44)$ & $0.95(0.62,1.43)$ \\
\hline Mixed & $0.70(0.45,1.08)$ & $0.68(0.42,1.09)$ \\
\hline European & REF & REF \\
\hline \multicolumn{3}{|l|}{ Essential worker } \\
\hline Yes & $0.74(0.55,0.99)$ & $0.74(0.55,1.00)$ \\
\hline No & REF & REF \\
\hline \multicolumn{3}{|l|}{ Number of people in the household } \\
\hline 4 or less & $0.84(0.61,1.16)$ & $0.88(0.63,1.24)$ \\
\hline 5 or more & REF & REF \\
\hline \multicolumn{3}{|l|}{ Household member age 60 or older } \\
\hline Yes & $1.26(0.80,1.97)$ & $1.31(0.87,1.98)$ \\
\hline No & REF & REF \\
\hline \multicolumn{3}{|l|}{ Child living arrangement ${ }^{3}$} \\
\hline One-parent or alternating household & $0.46(0.20,1.05)$ & $0.42(0.17,1.01)$ \\
\hline Both parents in the same household & REF & REF \\
\hline \multicolumn{3}{|l|}{ Child currently attends childcare } \\
\hline Yes & $1.00(0.69,1.45)$ & $0.98(0.67,1.44)$ \\
\hline No & REF & REF \\
\hline
\end{tabular}


Table 2 (continued)

\begin{tabular}{lll}
\hline Parent & & \\
\hline Explanatory variable & Unadjusted RR (95\% CI) & Adjusted RR $(95 \%$ CI) \\
\hline $\begin{array}{l}\text { Parent is currently pregnant } \\
\text { Yes }\end{array}$ & $0.96(0.54,1.69)$ & $1.01(0.57,1.79)$ \\
No & REF & REF \\
Family history of chronic disease & $1.00(0.76,1.31)$ & REF \\
Yes & REF & $0.77,1.33)$ \\
No & & \\
\hline${ }^{1}$ Risk ratios were adjusted for child age, child sex, parent age, parent sex, and weekly visit except for parent age which was adjusted for child age, child \\
sex, and parent sex, and parent sex which was adjusted for child age, child sex, and parent age \\
${ }^{2}$ Estimates provided for every 1-year increase in age
\end{tabular}

children predicted decreased likelihood of adherence in parents but the opposite in children, perhaps due to parents taking greater precautions for children while transporting children between houses. Interestingly, living in a household with 5 or more people predicted an increased likelihood of adherence in children, which could be due to the greater need to practice public health preventive measures in larger households to protect household members or less need to play or participate in activities outside the home.

We did not find evidence that a family history of chronic disease predicted adherence, in contrast with Papanastasiou et al. (2020) who found that chronic health conditions related to risk of complications from COVID-19 were associated with adherence to public health preventive measures (Papanastasiou et al., 2020). This could be due to our family history of chronic disease variable having been defined more broadly and to the younger age of our study participants. Further, we did not find evidence that living with older adults or pregnant persons predicted adherence, which could be attributed to a lack of targeted public health messaging.

Previous research appears to show a $U$-shaped trend for the relationship between income and adherence to public health preventive measures. Those with lower income $(<\$ 30,000)$ were less able to avoid public transportation and comply with quarantine (Brankston et al., 2020) while those with higher income ( $>\$ 110,000)$ were more likely to participate in activities with someone outside their household (Brankston et al., 2020). Another study found that living in a lower-income neighbourhood was associated with reduced physical distancing and working outside the home was the main reason (Jay et al., 2020). Individuals with lower income are overrepresented in public-facing work with high proximity to others (Public Health Ontario, 2020a) and may be less able to adhere, while those with higher incomes may have greater ability to adhere.
The present study found modest but non-significant evidence that having a family income between $\$ 60,000$ and $\$ 149,999$ as compared with $\$ 150,000$ or more predicted decreased likelihood of adherence in parents.

Similar to a previous study that investigated the relationship between race and adherence to public health preventive measures and did not find strong associations (Papageorge et al., 2021), we found no evidence that ethnicity was predictive of adherence. These findings may appear to conflict with local and provincial data demonstrating that COVID-19 disproportionately impacts racialized groups; however, to the best of our knowledge, there have been no population-based data on race or ethnicity as predictors of adherence to public health preventive measures in Canada. Data from Toronto Public Health showed that racialized individuals represented $83 \%$ of reported COVID-19 cases but made up 52\% of Toronto's population (City of Toronto, 2020), with similar trends in the United States and United Kingdom (Centers for Disease Control and Prevention, 2020; Chen \& Krieger, 2020; Mein, 2020; Office of National Statistics, 2020). Data from Toronto Public Health has also shown that individuals living in households considered lower income and in households with five or more people were overrepresented in COVID19 cases (City of Toronto, 2020). With respect to both income and ethnicity, our study does not represent all of the City of Toronto. We had a high-income sample where $57 \%$ of participants had a total family income of $\$ 150,000$ or more per year, while $19 \%$ of Torontonians had a total household income of $\$ 150,000$ or more based on 2015 estimates (Statistics Canada, 2017). Moreover, the majority of Torontonians are racialized (Statistics Canada, 2017) while 64\% of study participants were of European ethnicity on the maternal side and $71 \%$ on the paternal side. Both factors limit generalizability of our findings and are the primary reason we did not see an 
Table 3 Unadjusted and adjusted risk ratios (RR) and 95\% confidence intervals (CI) for the association between social determinants of health and children's average weekly adherence versus incomplete adherence during the COVID-19 pandemic from April to July 2020 ( $n=416$ unique children and 2632 repeated observations) estimated using marginal logbinomial regression models

Child

\begin{tabular}{|c|c|c|}
\hline Explanatory variable & Unadjusted RR (95\% CI) & Adjusted $\mathrm{RR}^{1}(95 \% \mathrm{CI})$ \\
\hline Child age ${ }^{2}$ & $1.00(0.97,1.02)$ & $0.97(0.94,1.00)$ \\
\hline \multicolumn{3}{|l|}{ Child sex } \\
\hline Female & $0.90(0.80,1.05)$ & $0.92(0.80,1.06)$ \\
\hline Male & REF & REF \\
\hline \multicolumn{3}{|l|}{ Family income } \\
\hline Less than $\$ 60,000$ & $0.98(0.74,1.30)$ & $1.03(0.78,1.37)$ \\
\hline$\$ 60,000$ to $\$ 149,999$ & $1.01(0.87,1.18)$ & $1.01(0.87,1.17)$ \\
\hline$\$ 150,000$ or more & REF & REF \\
\hline \multicolumn{3}{|l|}{ Median neighbourhood household income } \\
\hline Less than $\$ 60,000$ & $0.90(0.70,1.13)$ & $0.86(0.69,1.07)$ \\
\hline$\$ 60,000$ to $\$ 99,999$ & $0.94(0.77,1.16)$ & $0.94(0.78,1.14)$ \\
\hline$\$ 100,000$ or more & REF & REF \\
\hline \multicolumn{3}{|l|}{ Unemployed due to COVID-19 } \\
\hline Yes & $0.90(0.72,1.11)$ & $0.91(0.74,1.12)$ \\
\hline No & REF & REF \\
\hline \multicolumn{3}{|l|}{ Dwelling type } \\
\hline Apartment & $0.77(0.62,0.96)$ & $0.80(0.64,1.00)$ \\
\hline House & REF & REF \\
\hline \multicolumn{3}{|l|}{ Maternal ethnicity } \\
\hline African, Southeast Asian, South Asian & $0.96(0.78,1.19)$ & $1.00(0.82,1.21)$ \\
\hline Arab, Latin American, East Asian & $0.97(0.78,1.20)$ & $0.94(0.76,1.15)$ \\
\hline Mixed & $1.06(0.84,1.32)$ & $1.10(0.91,1.33)$ \\
\hline European & REF & REF \\
\hline \multicolumn{3}{|l|}{ Paternal ethnicity } \\
\hline African, Southeast Asian, South Asian & $1.04(0.86,1.26)$ & $1.05(0.86,1.27)$ \\
\hline Arab, Latin American, East Asian & $0.96(0.76,1.22)$ & $1.00(0.80,1.26)$ \\
\hline Mixed & $0.77(0.61,0.98)$ & $0.76(0.61,0.95)$ \\
\hline European & REF & REF \\
\hline \multicolumn{3}{|l|}{ Essential worker } \\
\hline Yes & $0.95(0.81,1.12)$ & $0.98(0.83,1.15)$ \\
\hline No & REF & REF \\
\hline \multicolumn{3}{|l|}{ Number of people in the household } \\
\hline 4 or less & $0.84(0.72,0.99)$ & $0.85(0.73,0.98)$ \\
\hline 5 or more & REF & REF \\
\hline \multicolumn{3}{|l|}{ Household member age 60 or older } \\
\hline Yes & $1.10(0.85,1.44)$ & $1.15(0.92,1.43)$ \\
\hline No & & REF \\
\hline \multicolumn{3}{|l|}{ Child living arrangement } \\
\hline One-parent household & $0.78(0.50,1.24)$ & $0.75(0.48,1.20)$ \\
\hline Alternating household & $2.18(1.33,3.57)$ & $1.34(0.98,1.84)$ \\
\hline Both parents in the same household & REF & REF \\
\hline \multicolumn{3}{|l|}{ Child currently attends childcare } \\
\hline Yes & $0.95(0.76,1.17)$ & $0.93(0.75,1.16)$ \\
\hline No & REF & REF \\
\hline
\end{tabular}


Table 3 (continued)

Child

\begin{tabular}{lll}
\hline Explanatory variable & Unadjusted RR (95\% CI) & Adjusted RR $^{1}(95 \%$ CI) \\
\hline Parent is currently pregnant & & $0.93(0.63,1.36)$ \\
Yes & $0.90(0.58,1.27)$ & REF \\
No & REF & $0.95(0.81,1.13)$ \\
Family history of chronic disease & & REF \\
Yes & $0.96(0.81,1.14)$ & REF \\
No & R & \\
\hline
\end{tabular}

${ }^{1}$ Risk ratios were adjusted for child age, child sex, parent age, parent sex, and weekly visit except for child age which was adjusted for child sex, parent age, and parent sex, and child sex which was adjusted for child age, parent sex, and parent age

${ }^{2}$ Estimates provided for every 1 -year increase in age

$C I$, confidence interval; $R R$, risk ratio; $R E F$, reference

association between ethnicity or income and adherence. The greater proportion of COVID-19 infection and outcomes in individuals who are racialized, lower income, or living in larger households may be explained by the influence of structural factors such as racism, social exclusion, and housing (Public Health Ontario, 2020a). These structural factors lead to the disproportionate number of racialized individuals working in essential worker jobs, taking public transportation, and living in crowded housing - all of which lack appropriate protections and lead to the inability to follow public health preventive measures.

To our knowledge, the current study is the first to explore the relationship between the SDOH and adherence to public health preventive measures among parents and young children during the COVID-19 pandemic. The study had several strengths, including the use of repeated individual measures, allowing for greater precision in estimates, and exploration of adherence to public health preventive measures over time. Limitations of this study include the relatively small sample size and relatively low follow-up rate. Furthermore, our study is nested within the TARGet Kids! primary care pediatric network and reflects parents and children recruited from selected primary care practices and is not a population-based representative sample. The sample had a relatively high income and education as compared with the overall population. The findings from this study may be not generalizable to other populations and national data on parents and children are needed. Furthermore, the potential for residual confounding (e.g., additional predictors not controlled for, unmeasured health conditions, primary mode of transportation, and neighbourhood density) as well as measurement error and desirability bias due to self-report is possible due to the nature of questionnaires. Unmeasured confounding could reduce the conservativeness of estimates while desirability bias could increase them. Last, the fast-paced nature of the pandemic created a lag between questionnaire development, administration, and completion, making it difficult to capture other measures of public health guidance like masking as the understanding of the pandemic and subsequent guidelines changed. Furthermore, at the time of questionnaire development, nuances regarding the adherence to public health measures were not asked, such as whether participants stayed at home for the whole day (or had outside time) and whether they avoided inperson contact with those they do not live with.

\section{Conclusion}

Public health preventive measures have been a necessary public health intervention in preventing COVID-19 transmission. Understanding the factors that facilitate or prevent adherence to these measures is important. In this study, we found that intermediary determinants of health, such as housing, employment, and child living arrangement, were predictive of adherence for parents but less so for their children. Equitable approaches to supporting parents in implementing public health preventive measures, especially for those unemployed, living in apartments, or having non-traditional child living arrangements, and appropriate workplace protections (e.g., plexiglass shields, masking, paid sick-leave policies) for essential workers, may help increase adherence to public health preventive measures. Future research is needed to understand the underlying reasons for decreased likelihood of adherence, including neighbourhood, public transportation, and other structural factors. Additionally, future research should investigate whether measures of protection are in place for situations where adherence to public health preventive measures is not possible. This research will help identify 
effective strategies to prevent COVID-19 transmission for atrisk families.

\section{Contributions to knowledge}

What does this study add to existing knowledge?

- This study contributes novel results describing the adherence to public health preventive measures among parents and children during the COVID-19 pandemic and an understanding of how social determinants of health are associated with adherence.

What are the key implications for public health interventions, practice, or policy?

- The results of this study may inform public health interventions or policy by identifying variables associated with lack of adherence to public health preventive measures during the COVID-19 pandemic.

Supplementary Information The online version contains supplementary material available at https://doi.org/10.17269/s41997-021-00540-5.

Availability of data and materials Data are available upon request by contacting www.targetkids.ca/contact-us/. The full data are not freely available in order to respect the confidentiality of our participants, ensure data integrity, and avoid scientific overlap between projects. Once initial contact has been made, we request a short research proposal which will be subject to review by the TARGet Kids! Scientific Committee and approval by institutional REB.

Code availability Code is available upon request by contacting the corresponding author.

Author contributions All authors conceptualized and designed the study. YY-M, CK-S, SW, and LA contributed to the analysis and interpretation of data. YY-M drafted the initial manuscript and reviewed and revised the manuscript. CSB and JLM coordinated and supervised data collection. CK-S, SW, XL, SMV, CMB, CSB, JLM, and LA reviewed the manuscript for important intellectual content.

Funding This study is financially supported by the Canadian Institutes of Health Research, and Fast grants.

\section{Declarations}

Ethics approval Ethics approval was provided by the Research Ethics Boards at both The Hospital for Sick Children and Unity Health Toronto.

Consent to participate Informed written consent was obtained from the parents at enrollment for the TARGet Kids! Cohort Study and informed verbal consent was provided over the telephone for the TARGet Kids! COVID-19 Study of Children and Families.

Consent for publication All authors approved the manuscript.
Conflict of interest The authors declare no competing interests.

\section{References}

Barari, S., Caria, S., Davola, A., Falco, P., Fetzer, T., Fiorin, S., et al. (2020). Evaluating COVID-19 public health messaging in Italy: self-reported compliance and growing mental health concerns. MedRxiv, 1-19. https://doi.org/10.1101/2020.03.27.20042820.

Brankston, G., Merkley, E., Fisman, D. N., Tuite, A. R., Poljak, Z., Loewen, P. J., \& Greer, A. L. (2020). Sociodemographic disparities in knowledge, practices, and ability to comply with COVID-19 public health measures in Canada. MedRxiv. https://doi.org/10.1101/ 2020.08.24.20180919.

Brouard, S., Vasilopoulos, P., \& Becher, M. (2020). Sociodemographic and psychological correlates of compliance with the Covid-19 public health measures in France. Canadian Journal of Political Science, 1-6. https://doi.org/10.1017/S0008423920000335.

Brzezinski, A., Kecht, V., Van Dijcke, D., \& Wright, A. L. (2020). Belief in science influences physical distancing in response to COVID-19 lockdown policies. SSRN Electronic Journal. https://doi.org/10. 2139/ssrn.3587990.

Canadian Women's Foundation. (2020). The facts: learn the reality about a pandemic's effect on women. https://canadianwomen.org/thefacts/women-and-pandemics/. Accessed 11 November 2020.

Carsley, S., Borkhoff, C. M., Maguire, J. L., Birken, C. S., Khovratovich, M., McCrindle, B., et al. (2015). Cohort profile: The Applied Research Group for Kids (TARGet Kids!). International Journal of Epidemiology, 44(3), 776-788. https://doi.org/10.1093/ije/ dyu123.

Carvalho, L. d. F., Pianowski, G., \& Gonçalves, A. P. (2020). Personality differences and COVID-19: are extroversion and conscientiousness personality traits associated with engagement with containment measures? Trends in Psychiatry and Psychotherapy, 42(2), 179184. https://doi.org/10.1590/2237-6089-2020-0029.

Centers for Disease Control and Prevention. (2020). COVID-19 hospitalization and death by race/ethnicity. https://www.cdc.gov/ coronavirus/2019-ncov/covid-data/investigations-discovery/ hospitalization-death-by-race-ethnicity.html. Accessed 24 November 2020

Chen, J., \& Krieger, N. (2020). Revealing the unequal burden of COVID19 by income, race/ethnicity, and household crowding: US county versus zip code analyses. Journal of Public Health Management and Practice. https://doi.org/10.1097/PHH.0000000000001263.

Chu, D. K., Akl, E. A., Duda, S., Solo, K., Yaacoub, S., Schünemann, H. J., et al. (2020). Physical distancing, face masks, and eye protection to prevent person-to-person transmission of SARS-CoV-2 and COVID-19: a systematic review and meta-analysis. The Lancet, 395(10242), 1973-1987. https://doi.org/10.1016/S0140-6736(20) 31142-9.

City of Toronto. (2020). COVID-19: Status of Cases in Toronto - City of Toronto. https://www.toronto.ca/home/covid-19/covid-19-latestcity-of-toronto-news/covid-19-status-of-cases-in-toronto/. Accessed 27 September 2020.

Detsky, A. S., \& Bogoch, I. I. (2020). COVID-19 in Canada. JAMA, 324 (8):743-744. https://doi.org/10.1001/jama.2020.14033.

Farias, J. E. M., \& Pilati, R. (2020). Violating social distancing amid the COVID-19 pandemic: psychological factors to improve compliance. PsyArXiv, 1-17. https://doi.org/10.31234/osf.io/apg9e.

Freeman, D., Waite, F., Rosebrock, L., Petit, A., Causier, C., East, A., et al. (2020). Coronavirus conspiracy beliefs, mistrust, and compliance with government guidelines in England. Psychological Medicine, 1-13. https://doi.org/10.1017/S0033291720001890.

Government of Canada. (2020). Coronavirus disease (COVID-19): Measures to reduce COVID-19 in your community. https://www. 
canada.ca/en/public-health/services/diseases/2019-novelcoronavirus-infection/prevention-risks/measures-reducecommunity.html. Accessed 11 September 2020.

Government of Ontario. (2020). Archived - Reopening Ontario in stages. https://www.ontario.ca/page/reopening-ontario-stages. Accessed 11 November 2020.

Guttmann, A., Gandhi, S., Wanigaratne, S., Lu, H., Ferreira-Legere, L. E., Paul, J., Gozdyra, P., Campbell, T., Chung, H., Fung, K., Chen, B., Kwong, J. C., Rosella, L., Shah, B. R., Saunders, N., Paterson J. M., Bronskill, S. E., Azimaee, M., Vermeulen, M. J., Schull, M. (2020). COVID-19 in Immigrants, Refugees and Other Newcomers in Ontario: Characteristics of Those Tested and Those Confirmed Positive, as of June 13, 2020. Toronto, ON: ICES.

Harper, C. A., Satchell, L. P., Fido, D., \& Latzman, R. D. (2020). Functional fear predicts public health compliance in the COVID19 pandemic. International Journal of Mental Health and Addiction, Apr 27:1-14. https://doi.org/10.1007/s11469-02000281-5. Epub ahead of print.

Jay, J., Bor, J., Nsoesie, E. O., Lipson, S. K., Jones, D. K., Galea, S., \& Raifman, J. (2020). Neighbourhood income and physical distancing during the COVID-19 pandemic in the United States. Nature Human Behaviour, 1-9. https://doi.org/10.1038/s41562-02000998-2.

Kissler, S. M., Tedijanto, C., Goldstein, E., Grad, Y. H., \& Lipsitch, M. (2020). Projecting the transmission dynamics of SARS-CoV-2 through the postpandemic period. Science, 368(6493), 860-868. https://doi.org/10.1126/science.abb5793.

Mein, S. A. (2020). COVID-19 and health disparities: The reality of "the great equalizer". Journal of General Internal Medicine, 35(8), 2439-2440. https://doi.org/10.1007/s11606-020-05880-5.

Office of National Statistics. (2020). Coronavirus (COVID-19) related deaths by ethnic group, England and Wales: 2 March 2020 to 15 May 2020. https://www.ons.gov.uk/peoplepopulationandcommunity/ birthsdeathsandmarriages/deaths/articles/ coronaviruscovid19relateddeathsbyethnicgroupenglandandwales/ 2march2020to15may2020. Accessed 11 September 2020.
Olcaysoy Okten, I., Gollwitzer, A., \& Oettingen, G. (2020). Gender differences in preventing the spread of coronavirus. PsyArXiv. https:// doi.org/10.31234/osf.io/ch4jy.

Ontario Agency for Health Protection and Promotion (Public Health Ontario). (2020a). COVID-19 - What we know so far about... social determinants of health. Toronto, ON: Queen's Printer for Ontario.

Ontario Agency for Health Protection and Promotion (Public Health Ontario). (2020b). COVID-19 pandemic school closure and reopening impacts. Toronto, ON: Queen's Printer for Ontario.

Papageorge, N. W., Zahn, M. V, Jamison, J. C., Tripodi, E., Jamison, J. C., \& Tripodi, E. (2021). Socio-demographic factors associated with self-protecting behavior during the COVID-19 pandemic. Journal of Population Economics, 34, 691-738. https://doi.org/10.1007/ s00148-020-00818-x.

Papanastasiou, A., Ruffle, B. J., \& Zheng, A. L. (2020). Compliance with social distancing: theory and empirical evidence from Ontario during COVID-19. http://www.mcmaster.ca/economics/. Accessed 15 October 2020

Rogers, R. G., Everett, B. G., Onge, J. M. S., \& Krueger, P. M. (2010). Social, behavioral, and biological factors, and sex differences in mortality. Demography, 47(3), 555-578. https://doi.org/10.1353/ dem.0.0119.

Statistics Canada. (2017). Population projections for Canada and its regions, 2011 to 2036. https://www150.statcan.gc.ca/n1/pub/91-551x/91-551-x2017001-eng.htm. Accessed 27 November 2019.

Travaglino, G., \& Moon, C. (2020). Explaining compliance with social distancing norms during the COVID-19 pandemic: the roles of cultural orientations, trust and self-conscious emotions in the US, Italy, and South Korea. PsyArXiv. https://doi.org/10.31234/osf.io/8yn5b.

Wilkins, R. (2009). PCCF+ Version 5E User's Guide. Automated Geographic Coding Based on the Statistics Canada Postal Code Conversion Files, Including Postal Codes through March 2009. Catalogue 82F0086-XDB. Ottawa: Health Analysis Division, Statistics Canada.

Publisher's note Springer Nature remains neutral with regard to jurisdictional claims in published maps and institutional affiliations. 